\title{
Enzymatic Determination of Glucose in Milk Samples by Sequential Injection Analysis
}

\author{
Alberto N. AraúJo, José L. F. C. Lima, Paula C. A. G. Pinto, and M. Lúcia M. F. S. Saraiva ${ }^{\dagger}$ \\ REQUIMTE, Serviço de Química-Física, Faculdade de Farmácia, Universidade do Porto, \\ Rua Aníbal Cunha 164, 4099-030 Porto, Portugal
}

\begin{abstract}
The present work describes a comparative study involving two sequential injection enzymatic procedures for the spectrophotometric determination of glucose in milk samples. The determinations were based on the use of the enzymes, glucose oxidase and peroxidase, in solution or immobilized, and 4-aminophenazone and phenol as chromogenic reagents. In the first procedure, $8.4 \mathrm{IU}$ of glucose oxidase and $0.5 \mathrm{IU}$ of peroxidase were consumed in each determination. In the second procedure, $107 \mathrm{IU}$ of glucose oxidase and $105 \mathrm{IU}$ of peroxidase, immobilized in glass beads, were sequentially packed into the same reactor. The reactor allowed us to perform about 600 continuous determinations with no activity loss. The proposed systems allowed the determination of glucose up to $120 \mathrm{mg} \mathrm{L}^{-1}$ in milk samples with a precision, considering the RSD (\%) values, lower than 3.5\%. The results obtained for the two systems were comparatively evaluated against a routine enzymatic method, showing a relative deviation of less than $3 \%$.
\end{abstract}

(Received June 12, 2008; Accepted December 12, 2008; Published May 10, 2009)

\section{Introduction}

The use of enzymatic methodologies, as key steps for the analysis of complex matrices has grown in the last decades, since it allows the implementation of expeditious procedures with high specificity. ${ }^{1}$ Besides this, the utilization of enzymes in analytical procedures avoids the use of hazardous reagents, thus reducing the production of toxic effluents, being such a good choice, considering the actual guidelines of green chemistry. ${ }^{2}$

The implementation of enzymatic procedures in an automatic flow system makes its use even more attractive since it allows the reproducible reduction of sample and reagent volumes and a decrease of the analysis time, making the procedures faster and more economic. ${ }^{1}$ An increasing number of flow-injection studies has described the utilization of enzymes in solution, immobilized in a solid material or as part of optical or electrochemical sensors. ${ }^{3-5}$ The inherent advantages of sequential injection analysis (SIA) techniques, such as versatility and simplicity, make them an excellent choice for the implementation of enzymatic procedures, allowing the development of robust methodologies. ${ }^{6}$ Furthermore, the versatility and flexibility of this technique associated with its low cost make it a useful analytical tool for complex matrices, namely food samples. ${ }^{7}$

The utilization of enzymes in solution, as part of flow procedures, has revealed some drawbacks, such as large enzyme consumption and a reduced sampling rate, so that in the last years the immobilization of enzymes in activated inert supports has markedly increased. ${ }^{8}$ However this alternative has been associated with carryover effects and flow resistance, and can involve the use of toxic reagents during immobilization. ${ }^{3}$ Being

† To whom correspondence should be addressed.

E-mail: 1saraiva@ff.up.pt so, the form of utilizing the enzyme will depend on the reaction and on the kind of sample involved, and must be comparatively studied.

The determination of glucose in food samples is nowadays a routine procedure that can be used to determine the degree of lactose digestion in low-lactose products ${ }^{9}$ and in the quality control of low-sugar foodstuffs. Most of the time the determination of glucose is performed using enzymatic kits ${ }^{10-13}$ involving enzymes as hexokinase, ${ }^{11}$ glucose-6-phosphate dehydrogenase ${ }^{12,13}$ and, preferentially, glucose oxidase (GOD). ${ }^{10}$ This enzyme has also been used in glucose determinations immobilized on oxygen optrodes, ${ }^{14}$ amperometric electrodes, ${ }^{15-20}$ nylon tubes using the $o$-alkylation method, ${ }^{21}$ aminopropyl glass beads, ${ }^{22-25}$ cellophane membranes, ${ }^{26}$ carbon nanotubes ${ }^{27}$ and more recently eggshell membranes ${ }^{28}$ that were, most of the time, incorporated in flow systems.

After the enzymatic reaction, the amount of glucose could be determined by spectrophotometric, ${ }^{4,29}$ fluorometric, ${ }^{30}$ amperometric ${ }^{16,25}$ and chemiluminometric ${ }^{24}$ methodologies.

In an attempt to provide a fast and automatic method for the routine analysis of glucose in milk products, the determination of glucose was implemented in two SIA systems. Due to its outstanding features, this technique seems to be ideal to develop applications for routine use. Its simple manifold reconfiguration, low reagent consumption and high independence on the operator are noteworthy advantages for daily use methodologies. Moreover, the objective and novelty of the proposed work relies on the development of a comparative study involving the enzymatic determination of glucose in milk samples, with soluble and immobilized catalysts, in order to establish two alternative SIA procedures that can be adapted to different routine situations.

In both situations, two enzymes were chosen: glucose oxidase, which catalyzes the oxidation of glucose by oxygen and peroxidase, which acts in the following reaction in which the 
hydrogen peroxide formed reacts with 4-aminophenazone and phenol, to form a colored compound monitored at $510 \mathrm{~nm} .{ }^{31}$ Since both enzymes can be employed either in solution or immobilized, ${ }^{32-34}$ each system exploited one of the possibilities, and therefore two SIA manifolds were developed and optimized: one using the enzymes in solution and the other one incorporating a tubular reactor in which the enzymes were immobilized.

\section{Experimental}

\section{Reagents and solutions}

All solutions were prepared using analytical-grade chemicals and deionized water with a specific conductance of less than 0.1 $\mu \mathrm{S} \mathrm{cm} \mathrm{cm}^{-1}$.

In the system involving the use of enzymes in solution (Fig. 1A), a $0.20 \mathrm{~mol} \mathrm{~L}^{-1}$ tris(hydroxymethyl)aminomethane (Tris) and $0.16 \mathrm{~mol} \mathrm{~L}^{-1} \mathrm{HCl}(\mathrm{pH}$ 7.4) buffer solution was used to prepare the enzymatic solution. For this purpose, a reagent strip of an enzymatic kit, for the determination of glucose (Peridochrom Glucose catalog No. 676543-Boehringer Mannheim, Germany), was immersed in $100 \mathrm{~mL}$ of this solution, which gave rise to a solution of $0.8 \mathrm{mmol} \mathrm{L}^{-1} 4$-aminophenazone and $11 \mathrm{mmol} \mathrm{L}^{-1}$ phenol. In this system deionized water was used as a carrier solution.

Regarding the assay with immobilized enzymes, for the color reaction a solution of $0.8 \mathrm{mmol} \mathrm{L}^{-1}$ 4-aminophenazone and 11 mmol L ${ }^{-1}$ phenol was prepared in a $0.038 \mathrm{~mol} \mathrm{~L}^{-1}$ Tris/0.030 mol L ${ }^{-1} \mathrm{HCl}(\mathrm{pH}$ 7.4) buffer solution, that was also used as a carrier solution (Fig. 1B).

D-Glucose standard solutions were prepared daily by dilution of a $2.00 \mathrm{~g} \mathrm{~L}^{-1}$ stock solution in water. The samples were deproteinized by adding $3 \mathrm{~mL}$ of $5 \%$ zinc sulfate and $3 \mathrm{~mL}$ of $5 \%$ barium hydroxide to $5 \mathrm{~mL}$ sample aliquots. The supernatant obtained after homogenization and centrifugation was introduced in the system without further treatment.

Glucose oxidase from Aspergillus niger (EC 1.1.3.4), Type V$\mathrm{S}, 1088$ units $\mathrm{mL}^{-1}$ and peroxidase from horseradish (EC 1.11.1.7), type VI, 290 units $\mathrm{mg}^{-1}$ were immobilized in aminopropyl glass beads $(200$ - 400 mesh, $107 \AA$ mean pore diameter), activated with a $2.5 \%$ glutaraldehyde solution.

The determination of glucose by the conventional method was carried out using a Boehringer UV-Kit for food analysis (catalog No. 716251 for D-glucose, Germany). ${ }^{13}$ This method is based on the enzymatic conversion of D-glucose to D-gluconate-6phosphate, by hexokinase and glucose-6-phosphate dehydrogenase, with the formation of reduced nicotinamideadenine dinucleotide phosphate (NADPH), whose amount measured at a wavelength of $340 \mathrm{~nm}$ was stoichiometrically related to the amount of D-glucose present in the samples.

\section{Bioreactor preparation}

The immobilization procedure was similar to that reported by Masoon and Townshend. ${ }^{35}$ Therefore, $0.25 \mathrm{~g}$ of aminoalkylated glass beads were incubated in $5 \mathrm{~mL}$ of $2.5 \%$ glutaraldehyde, in $0.1 \mathrm{~mol} \mathrm{~L}^{-1}$ phosphate buffer $(\mathrm{pH} 7.4)$, for one hour at room temperature, with brief nitrogen deoxygenation every $10 \mathrm{~min}$ in the first half hour. The activated glass beads (AGB) were washed with distilled water and $0.1 \mathrm{~mol} \mathrm{~L}^{-1}$ phosphate buffer. Immobilization was then performed by adding $1.5 \mathrm{~mL}$ of GOD or $4.3 \mathrm{mg}$ of peroxidase to $0.25 \mathrm{~g}$ of the AGB. After incubation at $4^{\circ} \mathrm{C}$ for $4 \mathrm{~h}$, in an oxygen-free atmosphere, the glass beads were then filtered off and washed first with distilled water, and then with phosphate buffer to eliminate any non-immobilized enzyme. Then, $21.1 \mathrm{mg}$ of immobilized peroxidase beads

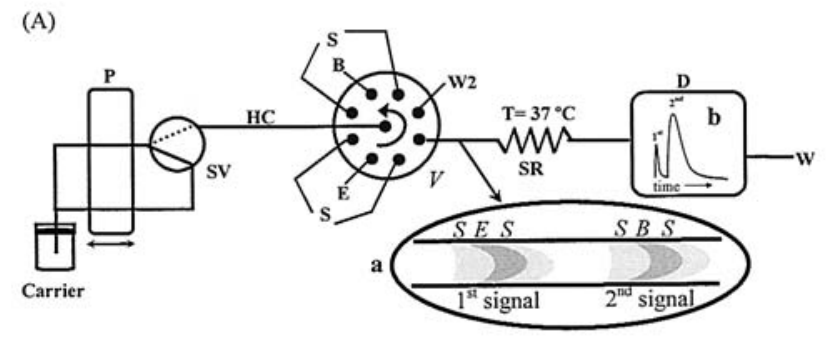

(B)

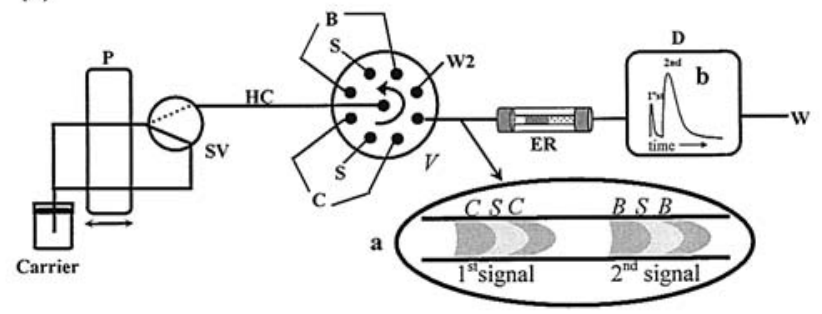

Fig. 1 Schematic representation of the SIA manifold for the determination of glucose: (A) with soluble enzymes, (B) with immobilized enzymes. P, Peristaltic pump; SV, solenoid valve; HC, holding coil $(300 \mathrm{~cm})$; V, selecting valve; D, detector; W, waste; S, sample or standard; B, buffer solution; E, enzymatic reagent; $\mathrm{C}$, color reagent; SR, serpentine reactor $(300 \mathrm{~cm})$; ER, enzymatic reactor; a, sequence of zones obtained in each analytical cycle; b, profile of signals obtained in each analytical cycle corresponding to the arrival of the sequence of zones to the detector.

(AGB-POD) and $16.4 \mathrm{mg}$ of immobilized glucose oxidase beads (AGB-GOD) were sequentially packed in the same Perspex column, of $20 \mathrm{~mm}$ length and $3 \mathrm{~mm}$ internal diameter. The imobilized enzyme beads were held in position with glass wool. When not in use the reactor was stored in $0.1 \mathrm{~mol} \mathrm{~L}^{-1}$ phosphate buffer, at $4^{\circ} \mathrm{C}$.

\section{Apparatus}

The solutions were propelled by a Gilson Minipuls 3 peristaltic pump, equipped with PVC pump tubing (1.4 mm i.d.). A Valco, Model Cheminert C15-3118E, 8-port valve (Valco, Instrument Co., Houston, TX) was used as the main selecting device and a Jenway 6300 spectrophotometer with a Hellma 178.712QS flow-through cell (18 $\mu \mathrm{L}$ internal volume) (Hellma GmbH \& Co. KG, Mullheim, Germany) was used as the detector device. All tubing connecting the different components of the SIA systems was made of Omnifit PTFE $0.8 \mathrm{~mm}$ (i.d.). A Variomag (Model E) thermostatic bath was used for temperature control in the system with enzymes in solution.

A Nresearch 161 T031 solenoid valve and a contact device (on the peristaltic pump), similar to the one described before by Araújo et al. ${ }^{36}$ controlled the pump starting point in order to guarantee reproducibility in the solution aspirated or propelled volumes.

All electrical devices of the manifold were computercontrolled by means of a home-made program written in Microsoft Qbasic 4.5. The computer was equipped with an Advantech PCL711B control interface card, which also allowed signal acquisition.

A Hitachi U2000 double-beam spectrophotometer was used to perform the glucose determination by the conventional method.

\section{Procedure}

The analytical cycle optimized for the determination of glucose based on the use of enzymes in solution (Table 1) begins 
Table 1 Analytical cycle for glucose determination in deproteinated milk samples

\begin{tabular}{|c|c|c|c|c|c|c|c|c|c|}
\hline \multirow{2}{*}{$\begin{array}{l}\text { Selection } \\
\text { valve }\end{array}$} & \multirow{2}{*}{$\begin{array}{l}\text { Pump } \\
\text { direction }\end{array}$} & \multicolumn{2}{|c|}{ Event } & \multicolumn{2}{|c|}{ Time/s } & \multicolumn{2}{|c|}{ 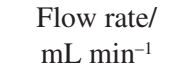 } & \multicolumn{2}{|c|}{ Volume/ $\mu \mathrm{L}$} \\
\hline & & A & B & A & B & A & B & A & B \\
\hline 1 & Aspiration & Sample & Buffer & 20 & 4 & 2.25 & 3.0 & 750 & 200 \\
\hline 2 & Aspiration & Buffer & Sample & 13 & 6 & 2.58 & 3.0 & 560 & 300 \\
\hline 3 & Aspiration & Sample & Buffer & 20 & 2 & 2.25 & 3.0 & 750 & 100 \\
\hline 4 & Propulsion & Detection & Detection & 320 & 190 & 1.1 & 1.0 & - & - \\
\hline 5 & Aspiration & Sample & Color reagent & 20 & 4 & 2.25 & 3.0 & 750 & 200 \\
\hline 6 & Aspiration & Enzymatic reagent & Sample & 13 & 6 & 2.58 & 3.0 & 560 & 300 \\
\hline 7 & Aspiration & Sample & Color reagent & 20 & 2 & 2.25 & 3.0 & 750 & 100 \\
\hline 8 & Propulsion & Detection & Detection & 320 & 190 & 1.1 & 1.0 & - & - \\
\hline
\end{tabular}

A, With soluble enzymes; B, with immobilized enzymes.

with the aspiration, to the holding coil, of an aliquot of Tris/HCl buffer sandwiched between two aliquots of a milk sample. After commutation of the valve and inversion of the flow direction, the solutions are propelled to the detector, through the thermostatically controlled reactor, in order to obtain a blank measurement. Then, an aliquot of the enzymatic reagent sandwiched between two aliquots of the sample are drawn up to the holding coil and redirected through the thermostatically controlled reactor, thus enabling the formation of the reaction product, which is monitored in the detector (Fig. 1A).

In the procedure based on the use of immobilized enzymes, an aliquot of sample is sandwiched between two aliquots of the buffer. In the second part of the cycle, the sample is sandwiched between two aliquots of the color reagent and an analytical cycle is obtained (Fig. 1B).

For sample replacement, a clean-up step was optimized: 150 $\mu \mathrm{L}$ of the new sample was introduced in the aspirating tube, with an inner volume of $50 \mu \mathrm{L}$; then, the aspirated sample fraction present in the holding coil was directly discarded before the next analytical cycle began.

\section{Results and Discussion}

\section{System optimization with soluble enzymes}

The developed SIA system incorporates a single bi-directional pump, a multiposition selector valve, and a detector, connected by low-diameter tubing, as main devices. The system relies on the time-based, sequential aspiration of well-defined sample and reagent zones into a holding coil, which are then redirected by flow reversal to the detector. During these steps, the sample and reagent zones inter-disperse with each other and in the region of mixing a product will be formed. ${ }^{6}$

The optimization of the chemical and physical parameters of the system began with the sample volume. Preliminary tests revealed that when small sample volumes were used, independently of the reagent volume, the amplitude of the obtained signal was not sufficient to adequately determine the glucose levels present in milk. This was only attained with sample volumes bigger than $1500 \mu \mathrm{L}$. Thus, to increase the overlap between the sample and reagent zones, and consequently the amount of formed product in the interfaces, the reagent was intercalated between two sample aliquots of $750 \mu \mathrm{L}$. The volume of reagent was therefore studied between 38 and 560 $\mu \mathrm{L}$, and an increase in the analytical signal of up to about $500 \%$ was observed. Higher volumes of the reagent did not lead to significant increases in the sensitivity; therefore, volumes of 560 and $1500 \mu \mathrm{L}$ of the reagent and the sample, respectively, were selected for subsequent studies. The incorporation of a serpentine reactor of $300 \mathrm{~cm}$, before the detector, led to the formation of a colored compound without significantly increasing the physical dispersion. This reactor was submerged in a thermostatic bath at $37^{\circ} \mathrm{C}$, the optimum temperature for the enzymes activity. The influence of the propulsion flow rate, between 2.3 and $0.5 \mathrm{~mL} \mathrm{~min}{ }^{-1}$, in the development of the enzymatic reaction and in the level of dispersion of the sample and the reagent zones as well as in the product formed, was evaluated. The obtained signals doubled when the flow rate decreased from 2.3 to $1.1 \mathrm{~mL} \mathrm{~min}^{-1}$. Since lower flow rates did not lead to any significant increase in the sensitivity, a flow rate of $1.1 \mathrm{~mL} \mathrm{~min}-1$ was adopted as a compromise between the amount of formed product and the dispersion. For aspiration of the solutions to the holding coil, a higher flow rate was used, in order to reduce the sampling time. After these preliminary evaluations, carried out with aqueous glucose solutions, the developed system was applied to deproteinated milk samples.

It was verified that milk samples originated an analytical signal, whose maximum corresponded to a residence time and amplitude different to that obtained with the calibration solutions. This behavior indicated differences in the mixture patterns between the samples and the calibrating solutions with the carrier which led to unequal buffering conditions for the samples and the calibrating solutions. In an attempt to equalize the conditions of enzymatic conversion of the calibration solutions and samples, inside the manifold tubing, the concentration of the Tris/ $\mathrm{HCl}$ buffer solution, used in the enzymatic reagent solution, was studied. Signals obtained in the concentration interval between $0.0250 \mathrm{~mol} \mathrm{~L}^{-1}$ Tris/ $0.02 \mathrm{~mol} \mathrm{~L}^{-1}$ $\mathrm{HCl}$ and $0.25 \mathrm{~mol} \mathrm{~L}^{-1}$ Tris $/ 0.2 \mathrm{~mol} \mathrm{~L}^{-1} \mathrm{HCl}$, were evaluated. A $0.2 \mathrm{~mol} \mathrm{~L}{ }^{-1}$ Tris $/ 0.16 \mathrm{~mol} \mathrm{~L}^{-1} \mathrm{HCl}$ solution was chosen for further studies, since it maximized the sample analytical signals. The optimized analytical cycle caused two analytical signals, with the first one being a blank measurement obtained with the sample, in the absence of the enzyme (Fig. 1Ab).

\section{System optimization with immobilized enzymes}

In this system the enzymes were immobilized and packed in a tubular reactor that was intercalated in the manifold between the selecting valve and the detector, since this position was the best option in terms of operational simplicity. Indeed, if placed in another valve entry, in a lateral position to the detector channel, this would imply the introduction of two further steps in the analytical cycle, one in which the sample was sent to the enzymatic reactor, and another related to aspiration of the product formed, to the holding coil. Only after these two steps the formed product could be sent to the detector. Furthermore, 
if the tubular reactor was placed in a lateral position, there would be not only an increase in the dispersion of the formed product, but also formation of preferential channels in the column leading to the liberation of dissolved gases in the solutions.

Since the enzymatic conversion of glucose is a two-step reaction, immobilized enzymes glass beads with glucose oxidase and peroxidase were placed in two distinct columns. The tubing length between the two enzymatic reactors was evaluated between 0 and $50 \mathrm{~cm}$, and higher analytical signals were obtained when this distance was minimal, due to the lower dispersion suffered by the first formed product, between the first and second columns. As a consequence, the two immobilizedenzyme glass beads were sequentially packed in the same column, and the optimization proceeded with an evaluation of the amount of immobilized glucose oxidase and peroxidase beads (AGB-GOD and AGB-POD, respectively). The amount of AGB-GOD was studied between 8.2 and $23.6 \mathrm{mg}$ and AGBPOD between 10.6 and $33.8 \mathrm{mg}$. An increase in the enzymatic conversion rate was observed up to $16.4 \mathrm{mg}$ of AGB-GOD and $21.1 \mathrm{mg}$ of AGB-POD, beyond which the increase of the analytical signal was not significant, under the conditions studied. It was also verified that when an amount of AGB-GOD or AGB-POD corresponding to the minimum values previously referred (8.2 and $10.6 \mathrm{mg}$, respectively) was used, the superior limit of glucose determination decreased, revealing a lack of enzymatic conversion in one of the reactions involved.

Since the immobilized enzymes were placed in the way to the detector, the carrier solution could not be deionized water, that caused a drastic reduction of column lifetime. Therefore, to guarantee the maintenance of enzymatic conversion rate through the determinations, a Tris/ $\mathrm{HCl}$ buffer solution was used as the carrier, at a flow rate of $1 \mathrm{~mL} \mathrm{~min}{ }^{-1}$. Higher flow rates limited the contact time of the sample and reagent zones, leading to a decrease in the enzymatic conversion. With these conditions,

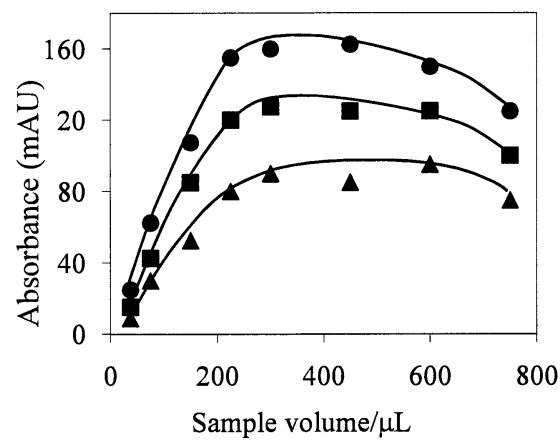

Fig. 2 Variation of analytical signal with the sample volume. Results obtained with calibration solutions of $60(\mathbf{\Delta}), 90(\boldsymbol{\square})$ and 120 (๑) $\mathrm{mg} \mathrm{L}^{-1}$. the reactor lifetime was superior to 2 weeks when used daily (6 h/day), being able to perform about 600 determinations with no activity loss.

4-Aminophenazone and phenol, also involved in the colorimetric determination of glucose, were dissolved in a Tris/ $\mathrm{HCl}$ buffer solution, and aspirated to the system through one of the valve entries. The reagents solution was aspirated in the system divided in two aliquots, intercalated by a sample segment, since this situation increased the mixture of the sample and the reagents, along the passage through the enzymatic reactor. The volume of the reagent was varied between 75 and $350 \mu \mathrm{L}$, and an increase in the amplitude of analytical signals was obtained when one aliquot of $200 \mu \mathrm{L}$ and another of $100 \mu \mathrm{L}$ of reagents solution were sequentially aspirated. The optimized sample volume, to intercalate in the reagent mixture, was 300 $\mu \mathrm{L}$, since bigger volumes did not lead to an increase in the sensitivity. Indeed, a stabilization of the signal up to 450 , followed by a subsequent fall-off, was observed (Fig. 2). This can be justified by insufficient dispersion of the sample aliquot in the reagents and dilution of the formed reaction product.

Finally, the concentration and $\mathrm{pH}$ of the buffer solution were optimized. The $\mathrm{pH}$ value was fixed at 7.4 , showing that the immobilization procedure did not change the optimum conditions for enzyme actuation. ${ }^{37}$ Several buffer solutions were also tested with concentrations between $0.012-0.15 \mathrm{~mol} \mathrm{~L}^{-1}$ of Tris and $0.01-0.12 \mathrm{~mol} \mathrm{~L}^{-1}$ of $\mathrm{HCl}$; it was observed that the $0.038 \mathrm{~mol} \mathrm{~L}^{-1}$ Tris $/ 0.03 \mathrm{~mol} \mathrm{~L}^{-1} \mathrm{HCl}$ solution enabled maximization of the enzymatic reactions.

The optimized analytical cycle (Table 1) involved 8 steps, in which the first four gave rise to a blank signal, whose absorbance value should be deducted from the value of the analytical signal obtained in the final stage (Fig. 1Bb).

\section{Analysis of milk samples}

The analytical performance of the developed SIA systems is summarized in Table 2. As shown, the system involving the use of enzymes in solution, even though it led to a smaller sampling frequency, allowed the analysis of samples with small concentrations of glucose with increased repeatability. This fact can be particularly interesting in the case of the analysis of sugar-free products that demand lower detection limits.

The optimized analytical systems (Table 2) were then applied to the analysis of 15 milk samples, and the accuracy of the proposed method was evaluated by comparing the average values with the results supplied by the Boehringer UV test (Table 3), frequently used in discrete analysis for this determination.

Considering the glucose concentrations present in samples, it can be verified that the results obtained by both SIA procedures were in fair agreement with those obtained by the conventional method. Generally, a comparison of the results obtained by the procedure involving the use of enzymes in solution and the conventional method resulted in deviations under $2.79 \%$ being

Table 2 Performance of the SIA system for the determination of glucose in deproteinated milk samples

\begin{tabular}{lcc}
\hline & $\mathrm{A}$ & $\mathrm{B}$ \\
\hline Regression equation $^{\mathrm{a}}$ & $Y=8( \pm 6)+2.71( \pm 0.07) X$ & $Y=-33( \pm 2)+2.66( \pm 0.03) X$ \\
Correlation coefficient, $r$ & 0.9993 & 0.9999 \\
Detection limit - upper limit/mg L & $7-120$ \\
RSD $(n=15)$ & $2.8 \%\left(53.8 \mathrm{mg} \mathrm{L}^{-1}\right)$ & $3.5 \%\left(59.8 \mathrm{mg} \mathrm{L}^{-1}\right)$ \\
Sampling frequency $/ \mathrm{h}^{-1}$ & 5 & 10 \\
\hline
\end{tabular}

A, With soluble enzymes; B, with immobilized enzymes. a. $Y=$ absorbance $(\mathrm{mAU}) ; X=$ glucose conc. $\left(\mathrm{mg} \mathrm{L}^{-1}\right) ; n=5$. 
Table 3 Results obtained in the determination of glucose in deproteinated milk samples, using the SIA procedures and the conventional batch method

\begin{tabular}{cccccc}
\hline & \multicolumn{5}{c}{ SIA/mg L } \\
Sample & $\begin{array}{c}\text { Soluble } \\
\text { enzyme }^{\mathrm{a}}\end{array}$ & $\mathrm{RD}, \%^{\mathrm{b}}$ & $\begin{array}{c}\text { Immobilized } \\
\text { enzyme }^{\mathrm{a}}\end{array}$ & $\mathrm{RD}, \%^{\mathrm{c}}$ & $\begin{array}{c}\text { Conventional } \\
\text { method }^{\mathrm{a}} \text { / } \\
\text { mg L }^{-1}\end{array}$ \\
\hline 1 & $62.5( \pm 0.9)$ & 0 & $64.4( \pm 0.7)$ & 3.04 & $62.5( \pm 0.8)$ \\
2 & $68.6( \pm 0.7)$ & -1.29 & $68.5( \pm 0.6)$ & -1.44 & $69.5( \pm 0.6)$ \\
3 & $73.2( \pm 0.9)$ & -2.79 & $73.9( \pm 0.9)$ & -1.86 & $75.3( \pm 0.6)$ \\
4 & $52.5( \pm 0.5)$ & 2.74 & $50.0( \pm 0.9)$ & -2.15 & $51.1( \pm 0.6)$ \\
5 & $65.5( \pm 0.9)$ & 0.15 & $65.0( \pm 0.5)$ & -0.61 & $65.4( \pm 0.7)$ \\
6 & $56.1( \pm 0.7)$ & 0.36 & $55.8( \pm 0.8)$ & -0.18 & $55.9( \pm 0.7)$ \\
7 & $65.5( \pm 0.8)$ & -0.61 & $65.0( \pm 0.7)$ & 1.36 & $65.9( \pm 0.7)$ \\
8 & $65.7( \pm 0.9)$ & -1.05 & $65.0( \pm 0.7)$ & -2.10 & $66.4( \pm 0.4)$ \\
9 & $76.1( \pm 0.8)$ & 0.53 & $76.4( \pm 0.9)$ & 0.92 & $75.7( \pm 0.7)$ \\
10 & $69.0( \pm 0.8)$ & 0.58 & $69.3( \pm 0.8)$ & 1.02 & $68.6( \pm 0.7)$ \\
11 & $71.2( \pm 0.9)$ & 0.71 & $70.7( \pm 0.9)$ & 0 & $70.7( \pm 0.9)$ \\
12 & $55.3( \pm 0.7)$ & 0.54 & $56.2( \pm 0.7)$ & 2.18 & $55.0( \pm 0.6)$ \\
13 & $64.2( \pm 0.8)$ & 0.31 & $64.2( \pm 0.7)$ & 0.31 & $64.0( \pm 0.5)$ \\
14 & $85.5( \pm 0.6)$ & 2.27 & $83.5( \pm 0.8)$ & -0.12 & $83.6( \pm 0.8)$ \\
15 & $66.8( \pm 0.8)$ & 0 & $66.8( \pm 0.6)$ & 0 & $66.8( \pm 0.9)$ \\
\hline
\end{tabular}

a. Mean and standard deviation of three consecutive determinations. b. Relative deviation from SIA procedure with soluble enzymes.

c. Relative deviation from SIA procedure with immobilized enzymes.

in most cases smaller than the deviation observed with the system with immobilized enzymes.

A linear relationship (SIA $\left.\left(\mathrm{mg} \mathrm{L}^{-1}\right)=C_{0}+S C_{\mathrm{c}}\left(\mathrm{mg} \mathrm{L}^{-1}\right)\right)$ was established along with the evaluation of $t$ (Student's $t$ test), obtained through carrying out a bilateral coupled test, as well as the theoretic $t$ value for a significance level of $95 \%$ (Table 4).

From analysis of the above-referred values, it can be observed that in both cases the calculated $t$ value, when compared with the tabulated value at the $95 \%$ confidence level, confirms the good agreement between the two methods, since the null hypothesis is accepted.

\section{Conclusions}

The developed SIA systems allowed the determination of glucose, at the levels in which it is present in milk and in lowlactose milk products. Resorting to one of the two developed systems did not require any significant physical reconfiguration of the system, as occurs in FIA systems. Effectively, the change of the reactor and few modifications in the analytical cycle allowed adaptation of the system to samples to be analyzed. Furthermore, the discontinuous flow nature, inherent to this automatic methodology, and the insertion of the solutions, in the system, on a time/flow rate basis, minimized the consumption of involved solutions, so important in enzymatic tests. Moreover, as far as we know, a comparative evaluation was done for the first time regarding the use of glucose oxidase and peroxidase, in solution or immobilized on a solid support. The developed study and the obtained results constitute an important feature in the field of flow enzymatic assays, since it illustrates, by means of the determination of glucose, the advantages and disadvantages of both approaches thus helping to adapt them to concrete routine situations.

Considering enzyme consumption, $8.4 \mathrm{IU}$ of glucose oxidase and $0.5 \mathrm{IU}$ of peroxidase were consumed in the determinations performed in the system based on the use of dissolved enzymes
Table 4 Parameters of the equation $C_{\mathrm{s}}=C_{0}+S C_{\mathrm{c}}$ for comparing the results $\left(\mathrm{mg} \mathrm{L}^{-1}\right)$ obtained by both SIA methodologies $\left(C_{\mathrm{s}}\right)$ and by the conventional procedure $\left(C_{\mathrm{c}}\right)$

\begin{tabular}{|c|c|c|c|c|c|}
\hline & $C_{0}$ & $S$ & $r^{\mathrm{a}}$ & $t_{0.025^{\mathrm{b}}}$ & $t_{0.025^{\mathrm{c}}}$ \\
\hline $\begin{array}{l}\text { Soluble } \\
\text { enzyme }\end{array}$ & $0.717( \pm 4.38)^{\mathrm{d}}$ & $0.991( \pm 0.064)^{\mathrm{d}}$ & 0.994 & 0.361 & 2.145 \\
\hline $\begin{array}{l}\text { Immobilized } \\
\text { enzyme }\end{array}$ & $0.692( \pm 4.53)^{\mathrm{d}}$ & $0.988( \pm 0.068)^{\mathrm{d}}$ & 0.993 & -0.456 & 2.145 \\
\hline
\end{tabular}

and $107 \mathrm{IU}$ of glucose oxidase and $105 \mathrm{IU}$ of peroxidase in the determinations involving the tubular enzymatic reactor. However the enzyme reactor with this amount of enzymes remained stable for long periods of time, thus allowing the analysis of 600 samples in continuous work. Furthermore, the system with tubular reactor allowed the analysis of about 10 samples per hour, being 2-times faster than that involving the use of enzymes in solution. It can be concluded that the use of immobilized enzymes is compensatory for the routine daily analysis of a big amount of samples, thus justifying the time and precision involved in preparing of the enzymatic reactor, which as already referred, are further compensated by the higher sampling rate. However, when the determinations are less frequent, or when turbid samples are involved, the system using enzymes in solution appears to be more adequate. Indeed, in this case the enzymatic consumption is restricted to the number of samples to analyze, and preparation of the enzymatic reagent is immediate and simple.

In any case, the optimized systems can be applied to the determination of glucose in other samples, as low-lactose products and sugar-free foodstuffs, since it is possible to obtain a blank signal to minimize any matrice interferences. It is also possible to adapt the system to the determination of other sugars, simply by introducing a preliminary conversion step of these sugars to glucose.

Furthermore, implementation of the developed SIA procedures enabled us to combine selectivity with the reproducible manipulation of small volumes of liquids, leading not only to a reduction in costs, but also to a fast and robust process.

\section{References}

1. M. Trojanowicz, "Enzymatic Methods of Detection and Immunoassays, Flow Injection Analysis: Instrumentation and Applications", 2000, World Scientific, Singapore, 162 200.

2. L. Giorno and E. Drioli, Tibtech, 2000, 18, 339.

3. N. Pizá, M. Miró, J. M. Estela, and V. Cerda, Anal. Chem., 2004, 76, 773.

4. S. M. Tzouwara-Karayanni and S. R. Crouch, Food Chem., 1990, 35, 109.

5. C. A. Tumang, E. P. Borges, and B. F. Reis, Anal. Chim. Acta, 2001, 438, 59

6. J. Ruzicka and G. D. Marshall, Anal. Chim. Acta, 1990 237, 329

7. R. Pérez-Olmos, J. C. Soto, N. Zárate, A. N. Araújo, J. L. F. C. Lima, and M. L. M. F. S. Saraiva, Food Chem., 2005, 90 , 471. 
8. P. L. Urban, D. M. Goodall, and N. C. Bruce, Biotechnol. Adv., 2006, 24, 42.

9. P. Jelen and O. Tossavainen, Aust. J. Dairy Technol., 2003, 58,161

10. Sigma-Aldrich Glucose Assay Kit (GO).

11. Sigma-Aldrich Glucose Assay Kit (HK).

12. Megazyme International Ireland Limited Glucose Assay Kit (HK).

13. Boehringer D-Glucose UV-Kit.

14. B. A. A. Dremel, B. P. H. Schaffar, and R. D. Schmid, Anal. Chim. Acta, 1989, 225, 293.

15. W. Matuszewski, M. Trojanowicz, and L. Ilcheva, Electroanalysis, 1990, 2, 147.

16. H. B. Qu, X. E. Zhang, and S. Z. Zhang, Food Chem., 1995, $52,187$.

17. M. Przybyt, Biosens. Bioelectron., 1998, 13, 471.

18. R. Pilloton, G. Mignogna, and A. Fortunato, Anal. Lett., 1994, 27, 833 .

19. X. N. Zhang and G. A. Rechnitz, Electroanalysis, 1994, 6, 361.

20. E. Watanabe, M. Takagi, S. Takei, M. Hoshi, and S. Cao, Biotechnol. Bioeng., 1991, 38, 99.

21. X. Liu and E. H. Hansen, Anal. Chim. Acta, 1996, 326, 1.

22. M. Manera, M. Miró, J. M. Estela, and V. Cerdá, Anal. Chim. Acta, 2004, 508, 23.
23. R. A. S. Lapa, J. L. F. C. Lima, and I. V. O. S. Pinto, Food Chem., 2003, 81, 141.

24. V. R. S. Babu, M. A. Kumar, N. G. Karanth, and M. S. Thakur, Biosens. Bioelectron., 2004, 19, 1337.

25. K. Matsumoto, H. Kamikado, H. Matsubara, and Y. Osajima, Anal. Chem., 1988, 60, 147.

26. L. Zajoncová, M. Jílek, V. Beranová, and P. Peč, Biosens. Bioelectron., 2004, 20, 240.

27. G. Liu and Y. Lin, Electrochem. Commun., 2006, 8, 251.

28. B. Li, D. Lan, and Z. Zhang, Anal. Biochem., 2008, 374, 64.

29. A. A. Suleiman, R. L. Villarta, and G. G. Guilbault, Anal. Lett., 1993, 26, 1493.

30. M. J. Valencia-González, Y. M. Liu, M. E. Díaz-Garcia, and A. Sanz-Medel, Anal. Chim. Acta, 1993, 283, 439.

31. P. Trinder, Ann. Clin. Biochem., 1969, 6, 24.

32. C. L. M. Stults, A. P. Wade, and S. R. Crouch, Anal. Chim. Acta, 1987, 192, 155.

33. L. Gorton and L. Ogren, Anal. Chim. Acta, 1981, 130, 45.

34. T. Taniai, A. Sakuragawa, and T. Okutani, Anal. Sci., 2000, 16, 517.

35. M. Masoon and A. Townshend, Anal. Chim. Acta, 1984, 166, 111.

36. A. N. Araújo, R. C. C. Costa, J. L. F. C. Lima, and B. F. Reis, Anal. Chim. Acta, 1998, 358, 111.

37. H. H. Weetall, Anal. Chem., 1974, 46, 602A. 